\title{
Generalization, epistemology and concrete: what can social sciences learn from the common sense of engineers
}

\author{
SIMONE TULUMELLO
}

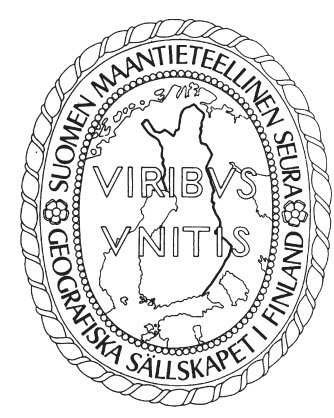

Tulumello, S. (2019) Generalization, epistemology and concrete: what can social sciences learn from the common sense of engineers. Fennia 197(1) 121-131. https://doi.org/10.11143/fennia.77626

$\mathbf{y}$ In this essay I debate critically, and somehow playfully, some assumptions and shortcomings of quantitative/positivist social research, using a dash of common sense typical of engineers. Civil engineers, in designing concrete structures, particularly those made up of concrete, have to continuously consider the error embedded in the limits of available systems of calculation, ending up adopting substantial factors of safety as counter-measures. The study of resistance of concrete structures is a good metaphor for social research; and yet, quantitative/ positivist researchers, in their search for "falsifiable generalizations", often forget about the omnipresence of error, let alone adopt the factors of safety. In short, the common sense of engineers is useful to casts some not-so-frequently-considered doubts over the capacity of quantitative methods and positivist epistemologies to create generalizable social science findings in face of uncertainty and the complexity of human societies. By casting such doubts, I advocate for a more relaxed (but not less rigorous) approach to social research and its complexity.

Keywords: epistemology, quantitative research, qualitative research, research methods, peer-review, falsifiable generalizations

Simone Tulumello, Universidade de Lisboa, Instituto de Ciências Sociais, Urban Transitions Hub, Av. Prof. A. Bettencourt 9, 1600-189, Lisbon, Portugal. E-mail: simone.tulumello@ics.ulisboa.pt

This essay is more than the result of my own ideas and work. Not only does its final form result from a lively and insightful conversation allowed by Fennia's open review process, but that very conversation continues within the text: having Guntram Herb, Jouni Häkli and Ossi Kotavaara generously agreed to publish their comments alongside my essay, I had the opportunity to explicitly engage with their insights. This allowed me to structure the essay as follows: the main text contains the main argument, which, for the sake of crafting a text I wanted to be provocative and engaging, is quite straightforward and direct - at times indeed reductionist; and I used footnotes quite heavily to provide nuance to the argument and engage in conversation with the reviewers' comments. As such, there are more ways to read this essay, with or without the footnotes, by itself or jumping back and forth to the three comments. I am thus very grateful to Guntram, Jouni and Ossi; and to Editor-in-Chief Kirsi Pauliina Kallio for offering the opportunity of the open review process and her support throughout the editorial process. I am also grateful to Pedro Magalhães, who read an older version of this essay and with whom I have discussed issues of epistemology several times. Though they may not be aware of that, I was inspired by discussions with a number of fellow scholars and friends, including Andy Inch, Andrea Pavoni, Eleonora Tulumello, Marco Allegra and Rui Costa Lopes. This notwithstanding, this essay's many shortcoming - and especially the insolence that may surface here and there - are my own responsibility.

URN:NBN:fi:tsv-oa77626

DOI: 10.11143/fennia.77626 (cc) BY (c) 2019 by the author. This open access article is licensed under a Creative Commons Attribution 4.0 International License. 


\section{Prologue: a qualitative researcher's Reviewer 2}

As a researcher that has been mainly, indeed almost exclusively, employing qualitative methods and case study research, I have lost the count of the times a peer-reviewer has criticized my work on the basis of the refrain "thou shalt not generalize from one case!" When it happens, that is, almost every time I submit an article, my first reaction is I want to write the editors an angry response, something on the lines of: "Dear Editors, please provide peer-reviewers with the actual competences to assess case study research, that is, judge whether, in light of the assumptions of case study research, my article is capable (or not) of building that kind of theory that (a fitting reviewer must know!) case study can indeed produce." ${ }^{\prime 1}$

But then, most often, once I have read the feedbacks and editorial decision, I would take a few days to let off steam, before sitting down and decide what to do. Eventually, if I was lucky enough to get a Major Revision or Revise and Resubmit (that kind of reviews is never followed by requests of Minor Revision), I would give up. I would expand the methodological section with more references on "how to theorize from case study research", temper the tone of the discussion and add a line in the conclusions that sounds like: "Although the preliminary findings of this article need to be confirmed by further research with wider panels of data, we can set out the following conclusions..." Although they usually help clearing the peer-review and have the paper published (as my fellows precarious researchers out there know, this is not a secondary matter), these changes signal an implicit abdication to the (allegedly) superior role of generalization to that of theorization in knowledge production - and, besides, they take space (the word limit...) that could be more profitably used to provide a better description of the case or theoretical discussion.

One of the last times this happened, I shared my frustration on the Facebook page Reviewer 2 Must Be Stopped, which is frequented by scholars from the most different backgrounds, ensuing a lively debate among those that were sympathetic with my frustration and those who would insist I cannot generalize from one single case. ${ }^{2}$ There is one simple evidence coming out from this, and other, more rigorous, debates (e.g. Flyvbjerg 2004, 285-286): While qualitative social scientists, and especially those working with case studies, ${ }^{3}$ are often even too conscious of the assumptions behind, and the shortcomings of, their epistemological approaches, quantitative/positivist ${ }^{4}$ researchers tend to consider "real science" that which stems from their epistemological assumptions only - most often, analyses over statistically significant samples or experiments said to produce "falsifiable generalizations". ${ }^{5}$ For instance, most methodological works about case study research are extremely, if often excessively, cautious, as if their authors were expecting at any moment a Reviewer 2 to shout "thou shalt not generalize from one case!"6 On the contrary, in articles grounded on a quantitative/ positivist paradigm, I have barely found explicit discussions of the epistemological assumptions and shortcomings of those methods: those assumptions go without saying, so to speak, and their shortcomings are easily forgotten, let alone debated (but see Pepinski 2016, for an exception). ${ }^{7}$

In this essay, I will debate, somehow playfully, some of those assumptions and shortcomings, using a dash of common sense typical of engineers - before embracing human geography and social sciences, I took a master's in civil-engineering. The common sense of engineers, I will suggest, casts some not-so-frequently-considered doubts over the capacity of quantitative methods and positivist epistemologies to create generalizable social science findings. By casting such doubts, I hope to contribute to a more relaxed (but not less rigorous) approach to social research and its complexity.

\section{Some insolent remarks on quantitative research}

Quantitative, positivistic-oriented social research works, to put it bluntly, through the creation of simplified models of social phenomena. By simplification I mean the process by which the researcher would select a number of variables they consider sufficient and adequate to create a realistic model, that is, a model capable of describing a given (social) phenomenon with acceptable accuracy. More variables, and more nuanced relations among the variables, more reliable the model will be, but at the cost of more work and computation. The perfect model, the society itself, is made up of an infinite number of variables, hence the need for infinite time to collect data and infinite time to process 
findings - Werner Heisenberg's uncertainty principle (published in 1927) made precisely this point with regard to physics. ${ }^{8}$ The core of the "scientific" work quantitative/positivist researchers do, apart from the mechanic work of collecting data and running the models, is deciding what variables, hence what data, are to be used and how to create links among those variables. In so doing, the researchers obviously influence the results on the grounds of their judgment - unfortunately however, in the public domain this is as obvious as Edgar Allan Poe's Purloined Letter. In Flyvbjerg's (2006, 235) words:

The element of arbitrary subjectivism will be significant in the choice of categories and variables for a quantitative or structural investigation, such as a structured questionnaire to be used across a large sample of cases. And the probability is high that (1) this subjectivism survives without being thoroughly corrected during the study and (2) that it may affect the results, quite simply because the quantitative/structural researcher does not get as close to those under study as does the casestudy researcher and therefore is less likely to be corrected by the study objects "talking back".

Put in other words, all social scientists employ judgment based on their epistemological and theoretical assumptions. While qualitative researchers employ it mainly "downstream", that is, when critically interpreting their findings; quantitative/positivist scientists employ most of it "upstream", that is, in the design of the models. ${ }^{9}$ It is exactly the placement of judgment upstream the production of findings that which creates the illusion quantitative/positivist science is "objective". This is the very first reason to be skeptical of the alleged superior capacity of quantitative research to produce generalized theory, when compared with qualitative research. To move a step further, let me now use a dash of engineering common sense.

\section{Studying civil engineering; and a ventured metaphor}

To begin with, let me briefly outline the way civil engineers are trained in Italy. During the first couple of years (of five, my degree was an integrated bachelor/master), the aspiring engineers would study almost exclusively theoretical classes such as Mathematical Analysis, Geometry, Classical Physics. In these classes, theoretical problems are always resolved through rigorous mathematical methods. During these years, "error" means the same as "mistake". During the third year, the aspiring engineers would study Building Science (Scienza delle Costruzioni), which starts as a theoretical class too. The students would learn the mathematics behind the equations that could, theoretically, solve any real structural problem. But, one day midway through the course, the professor would say that, unfortunately, there is no way to solve those equations with mathematical methods: they are too complex. Some simplifications are then introduced that allow the equations to be solved, but at the cost of introducing elements of uncertainty to the solution. For the first time, the aspiring engineers are faced with the existence of the error. The following year, in the course Building Techniques (Tecnica delle Costruzioni), the aspiring engineers would learn how to calculate a real structure, being introduced to further problems with mathematics and practice: on the one hand, that even the simplified equations they had learned in Building Science cannot be solved once they are applied to complex structures typical of real life; and, on the other, that it is not even possible to know with absolute precision the load real materials are capable of absorbing before breaking. Eventually, the engineers will be trained to use the software they will employ in their profession, software that uses simplified models of structures.

This organization of the degree may well be delusional for some students; but I happened to enjoy it, because it forces the aspiring engineers to face several crises of their previous knowledge, thus stimulating them to keep searching for different ways to solve problems. Moreover, this process trains engineers to preliminarily assess the resistance of structures at a first sight: they learn how to look at the preliminary design of a structure and rapidly assess whether it may be feasible, how it may be feasible and - what else could be more important in a capitalist world? - how much it could cost. This common sense helps engineers in several ways: while calculating a structure, they will start running tentative models, which will not be too far from the final one; or, they would usually be capable of warning the architects pretty early that the particular structure they have in mind will probably not be feasible (or would cost much more than they are trying to sell to their clients) before spending time in running complex models. At the same time, and crucially for my argument, engineers are trained to recognize where errors appear, and estimate their magnitude before calculating structures. 
Because of the use of simplified models and the resulting errors, engineers would eventually apply a factor of safety to their results, meaning that they will load the real structure with a fraction of the maximum loads the model can resist. The factor of safety depends on both the geometry of the structure (an estimation of the calculation error) and the material used. With regard to materials, the factor of safety is smaller when using steel (in common structures, less than 10\%), which is a homogeneous and highly predictable material. The factor of safety becomes much bigger for concrete: In common concrete structures it can go up to $50 \%$ - meaning that the structure will be designed to resist 1.5 times the maximum real loads.

The factor of safety is particularly high for concrete because of its complexity. Concrete is a composite, made of coarse aggregate (sand, gravel, crushed stones) bonded together with fluid cement. The variables that determine the strength of concrete are several: at the macro level, the average size of aggregate grains, the quality of the cement, and the proportion of aggregate, cement and water used; at the micro level, the ways the various grains and the cement are organized (the distance between grains, the respective position of edges and surfaces).

The point I want to make here is that the study of the resistance of structures made up of concrete works as a good metaphor for social research. ${ }^{10}$ Let's say each grain represents an individual human being, while the cement is the bond of relationships and affects among them, characterized by complex mutual tensions. The whole structure, the society, is made up of pillars and beams (and interactions thereof), that is, interacting sub-divisions of the society: families, groups, communities, classes, races, genders, you name it. Qualitative case study research can be seen, from this perspective, as the in-depth study of a small piece of concrete looking at the micro-variables. Quantitative social science can be seen as the study of the resistance of the entire structure, or of a part of it (a beam, a pillar, a node...) through macro-level variables (shape, estimated resistance of the concrete...).

\section{The day I remembered of my engineering training}

Keeping this in mind, let me recall the day my rusty engineering common sense was awaken while I was reading quantitative social findings. During the very same days I was discussing what is "real science" on Reviewer 2 Must Be Stopped, I happened to read an article on crime and security in US cities by Ellen, Lens and O'Regan (2012). The article has a very ambitious and important goal, that is, testing the commonplace that housing vouchers policies heighten crime. In the USA, housing vouchers have been given to households previously living in public housing "projects", where crime rates tend to be high; and, the commonplace goes, the displacement and dispersion of those households will displace and disperse crime, which will thus increase in the neighborhoods of destination. Indeed, rich evidence exists of the correlation between settlement of households with vouchers and crime increase. ${ }^{11}$ However, the causal relation has always been given for granted, but never "scientifically" verified, in public and even some academic debates - a process that accurately defines a "commonplace". ${ }^{12}$ Ellen and her colleagues thence decided to study those causal relations, using a longitudinal analysis (1996-2008) and regression models over panel data at the census tract level from 10 large US cities. Not only does the article cast serious doubts on the commonplace, but it finds some evidence of the reverse causal history: the authors conclude that voucher holders may tend to move to neighborhoods where crime is already increasing - there, rental prices may be lower for that very reason and more landlords may then accept to rent in the voucher market.

While I was reading the article, I could feel my engineering common sense raising the eyebrows. Let me put this very clear, I am not criticizing the validity or the rigor of the article: it is well written, rigorous in the use of methodology and convincing in its line of thought; and, though I have no specific skills to judge the regressions, the article cleared peer-review in a good journal and I thus give for granted the quantitative work was well done. Not the quality of the research, rather the underlying epistemological assumptions about the capacity of these methods to generalize social science findings stimulated my engineering common sense - in short, let me be Reviewer 2, for once.

So, what is the problem? As every experienced researcher knows, collecting data about human beings and their interactions is everything but a simple task. In order to collect perfect data and be capable of picking the variables that best fit a model, the researchers should have access to every 
possible information about each individual in the population "sample". Of course, collecting all possible data on every individual would entail immense amount of work, including detailed ethnographies. While following the "objects" of study in their daily life, and paraphrasing what Werner Heisenberg's uncertainty principle has taught us, the better ethnographic data is collected, the more the action of the "objects" of study is influenced. ${ }^{13}$ Back to our concrete, perfect data means knowing without margin of error the size and shape of every grain and its exact position: to do this, we have no other chance but ultimately break it. Indeed, researchers accustomed to participant observation and action research are well aware of their role in changing the very processes they are observing.

This is why quantitative/positivist researchers, whose aim is studying social phenomena without influencing them, use above all aggregated data collected by other parties (statistical data) or data provided by the "objects" of study themselves (surveys) - they construct a simplification of the average composition of the concrete and look more widely at the structure, or maybe one specific pillar or beam. This mediation creates error, because statistical data is always a simplification of the reality and surveys, well, for instance there really is no way to know the extent to which the respondent is being sincere.

This is well evident in the article by Ellen and her colleagues (2012). The authors use administrative data and admit they have faced important challenges. ${ }^{14}$ The authors employ several smart tactics to deal with such challenges, using linear interpolations among available data, comparing models that make or make not use of problematic data, comparing the whole model with a smaller model where cities with problems with data have been removed. The point is, there is no exact way to measure the error that the aggregate effect of such problems will produce. In fact, "error" is barely quantified in this kind of studies - with the exception of the statistical error of regressions.

Let me stress that these problems with data are not specific to this particular article: every set of statistical or aggregated data suffer of some kind of error for, as the principle of uncertainty tells us, there is no way to collect perfect data about any given phenomenon without influencing it. I know Reviewer 2 is ready to shout at me I am generalizing from one single case, but the harsh reality is there is no quantitative/positivist study that does not suffer of some problem with data - if Reviewer 2 has some doubts, they may want to pick a statistically significant sample of said articles and look into them, one after the other. Moreover, and this is another common issue with this kind of articles, Ellen and her colleagues (2012) do not discuss whether, and with what accuracy, are the 10 selected cities representative of the urban USA.

So, what does this mean for the main finding of the research, the value of the variable chosen to test the causal history reverse to the commonplace? According to linear regressions, the variable is statistically significant in the three models used: $0.167(p<0.01), 0.157(p<0.05)$ and $0.160(p<0.05)$ (Ellen et al. 2012, Table 4). This means that, according to the data available and their causal model, a household with voucher will be about $16 \%$ more likely to move to a census tract where crime increased in the previous year. The engineer in me would ask, what is the margin of error of the model? Is it 0.05 (meaning that the likeliness in the real world would still be positive, between 11 and 21\%)? Or is it 0.20 (meaning that the likeliness in the real world could be between $37 \%$ or slightly negative)? Looking at the size of problems with data, my engineering common sense suggests, I am afraid, that the latter is more likely than the former.

\section{Against generalization?}

Again, my goal here is not falsifying the robust findings a rigorous research has produced in light of its epistemological assumptions. This is to say, in light of such assumptions, taking in consideration the risk that voucher holders may end up moving to neighborhoods where crime is already increasing makes a lot of sense, both conceptually and practically. These findings help better understand the effects of vouchers (e.g. reconsider "freedom of choice" rhetoric) and support a more informed policy decision at the local level (e.g. in extremely unequal and segregated cities, vouchers not accompanied by further policies may cause more problems than those they solve). As for the "generalization" of a socio-spatial trend ("where do voucher holders go?"), however, we have no way to be sure what the margin of error is and, frankly, I do not think there is a way to be. Does anyone know of any method 
to systematically measure the error of quantitative/positivist social research (the error with data, the error with the simplification made by the model, and the cumulated error of both)?

Remember, engineers use factors of safety precisely to account for the impossibility to determine the error with accuracy. And, for a complex material like concrete, it is a very big factor, most often too big. But it is written down in laws, because we all acknowledge that protecting houses from crumbling down is more important than wasting some construction material: legal protections of this kind show the capacity, in the political and public sphere, to understand the limits of engineering studies and research. Surprisingly, the political and public discourses seem to have much less capacity to discern the limits of generalizations made in quantitative/positivist social research, which, by the way, can produce more significant damages than a house crumbling down. ${ }^{15}$ The magnitude of damages of the economic crisis started in 2007, together with the role certain assumptions and certain models used to "predict" how markets work had in creating the conditions for the crisis, is a case in point. ${ }^{16}$

\section{So what? Taking research cum grano salis}

I could have stopped here, but this is exactly where Flyvbjerg (2001) would ask the "so what" question. What is the point of my critique? Or, what does an engineering common sense suggest to social scientists? On the one hand, it suggests qualitative scientists to be aware that the particular piece of concrete they are studying may not represent the whole structure - and, as we all know, this is pretty well accepted among reviewers, particularly Reviewer 2. On the other hand, it suggests quantitative/ positivist scientists to remember to always use very big factors of safety when interpreting their findings, inasmuch as human societies are at least as complex as concrete - to be honest, much more complex, if anything because concrete changes very slowly in time. ${ }^{17}$ Unfortunately, this latter suggestion is barely heard around, let alone listened to.

Now, I am not suggesting Reviewer 2 to shout loud "thou shalt not generalize from panel data findings!" - while, I am afraid, this is at least as valid a claim as "thou shalt not generalize from one case!" What I am advocating is that it is high time we accept taking the generalizations of social phenomena based on panels of actually-existing data cum grano salis, that is, with the same caution we take theory produced through qualitative research. We need to learn that there is no such thing as "real science" and "hard data", as opposed to "high-quality journalism" (as several positivist scientists still consider ethnography and qualitative research) - quite the opposite, that the alleged objectiveness of some methods is a sharp way to conceal judgment within the process. On the contrary, social research would benefit a lot by the internalization that our work is always contingent to some assumptions, that is, the acceptance of the very irreducibility and different value of findings produced through different methodological and epistemological lenses. Is not, after all, Reviewer 2 basically the incapacity to accept such an irreducibility and the pretense to force one's assumptions upon others' research? ${ }^{18}$ Is not Reviewer 2 the incapacity to accept that generalization is not the hallmark of social research, and that the production of theory - as opposed to laws - is as relevant an endeavor?

In conclusion, and beyond the politics of peer-review, are we ready to embrace the fact that contradictions are inherent expressions of the complexity of the human (and non-human) world? ${ }^{19}$

And, well, let me conclude with a personal suggestion. Always discuss your research ideas and methods with an engineer before running complex models or making lengthy on-field research: that can help save a lot of time!

\section{Epilogue: the shelter we have}

(Social) science has been traditionally imagined as a gothic cathedral, a perfect construction that will be completed and perfected in the moment the keystone will be put in its place. Of course, scientists have always been aware that the process was complex, slow and painful; and that external events may had forced reconstructing a part or even reconsidering something in the foundations. But the keystone has always been, and still seems to be for many, the ultimate goal, the ultimate answer "42!", Douglas Adams would say. ${ }^{20}$ 
Then, this has been put into debate, from the uncertainty principle all the way to deconstruction, post-structuralism, post-modernism and the like. In time, the building has been savaged and seems now to be more a messy structure made up of ruins, shining glasses, shacks. There is the neoclassic glass and steel skyscraper from which economists enjoy the real world follow different paths, while sipping champagne, blaming state regulation, and accusing people and politicians of not abiding by the rules of the system. There is the post-structuralist field of ruins of the relentless critique, where the "so what" question echoes perennially. The construction seems to be now made up of parts that do not interact or, worst, create mutual structural problems. ${ }^{21}$

But, after all, it is important to acknowledge the scientific construction for its fragility, not solidity; for its continuous need of maintenance, refurbishing and restructuring. For, precarious as it is, it is the only shelter we have.

\section{Notes}

${ }^{1}$ Throughout the text, I distinguish purposefully between generalization and theory as two rather different goals of social research and knowledge production (see especially the concluding section "So what?") - Jouni Häkli suggested I should pay special attention to this distinction.

${ }^{2}$ Reviewer 2 Must Be Stopped is a quasi-ironic forum for sharing hanger and discussing bad peerreview. The discussion is publicly available here: www.facebook.com/groups/reviewer2/ permalink/10153956215715469/.

${ }^{3}$ Here and afterwards, I use case study as the main point of reference when discussing qualitative methodological approaches for two reasons: first, because it has recently assumed a central role in qualitatively-oriented urban and geographic research; and, second, because it is the methodology I have most experience with.

${ }^{4}$ Let us not forget - as Ossi Kotavaara and Guntram Herb correctly pointed out - that not all quantitative research seeks, from a positivist paradigm, to build global societal "laws", thence the use of "quantitative/positivist" throughout the text.

${ }^{5}$ I am aware that the dichotomic opposition I adopt throughout the essay is a simplification of the landscape of social research - and, at times, runs the risk of building two "caricatures", as pointed out by Jouni Häkli. For one, the dichotomy qualitative versus quantitative/positivist methodologies/ epistemologies is often fuzzy, as there is a growing "gray area" (a definition suggested by Häkli) made up of experimentation with different approaches, the use of mixed methods and cross-fertilization among long-separated methodological and epistemological "fronts". In retrospect, Hanson (2008) argues that the dichotomy is more "apparent than real" throughout the history of social research. More recently, a group of scholars based at the Sciences Po Médialab (founded by Bruno Latour) has developed an argument about the capacity of digital methods and big data analysis to overcome the quantitative/qualitative divide, creating a more "continuous" sociology (Venturini et al. 2017). And yet, the reality of actually-existing social research is characterized by fierce debate and contraposition among different schools of thought, the consequences of which we all have, sooner or later, came to experience, for instance when receiving a report by Reviewer 2 .

Guntram Herb also spotted an imbalance in the quantitative/positivist versus qualitative dichotomy. Indeed, methods and epistemologies are not straightforwardly and directly associated (see Bryman 1984, for a discussion). And yet, with regard to the argument I develop on the relationship between methodologies/epistemologies and the production of social research, I see that, independently from their epistemological orientation, qualitatively-oriented scholars more or less agree on the limits of their own epistemological assumptions - and hence "qualitative research", throughout the text, means "qualitative research informed by a diverse set of epistemological assumptions". At any rate, I agree with Herb where he suggested I owe the reader sharing openly my own approach, because this informs my perspective over the issues at stake. I see my personal epistemological endeavor as the search for critical theory, which I understand to have a twofold meaning: on the one hand, "a ruthless criticism of everything existing, ruthless in two senses: the criticism must not be afraid of its own conclusions, nor of conflict with the powers that be" (Marx 1978 [1844], 13; emphasis in the translation 
quoted); and, on the other hand, a theory that seeks to foster, inform and support transformative action (see Marcuse 2010).

${ }^{6}$ Even Yin (1994), author of Case Study Research, now at its sixth revised edition and possibly the most used reference in this field, seems to believe case study is a minor research method that, being incapable of building "social science generalizations", should mostly be used as a preliminary or exploratory tool. Another example of this approach is an otherwise adorable article on persuasion in case study research by Suggelkow $(2007)$. Flyvbjerg $(2004,2006)$ is, to the best of my knowledge, the scholar that has been most straightforward in advocating for, and fully exploiting, the potentialities of case study research for theorization.

7 This may not be particularly the case for human geography, Ossi Kotavaara suggests. I agree, and wish to speculate that this may be in part due to the relatively young history of human geography when compared to disciplines such sociology, anthropology or political science - all disciplines with longer and fiercer epistemological/methodological debates, from which human geography could learn from. The main target of my reflection is what Kotavaara suggested terming the "quantitative positivist paradigm or discourse" (a definition I fully embrace). What prompted me to write this essay is that it seems to me that the quantitative/positivist paradigm is still pretty strong within the whole body of social sciences - maybe not as an ideology but indeed as a "practice" of research and research evaluation (see Flyvbjerg 2004, 285-286) - and in particular in disciplines like sociology, social psychology or political science (e.g. Desch 2019).

${ }^{8}$ According to uncertainty, there is no way to know with absolute accuracy both the position and speed of a particle at a given moment, because the more careful the observation, the bigger the impact over the particle's trajectory. One of the implications is that forecasting the future trajectory of a single particle - and by extension of any system - is, pure and simply, impossible. It is quite surprising to me how this principle, a basic tenet of natural sciences, is basically ignored in many strands of social sciences, where it should be a truism. The ultimate version of the refusal to acknowledge uncertainty in social sciences is epitomized in grand claims, by some advocates of big data, about the "end of theory": "Scientists no longer have to make educated guesses, construct hypotheses and models, and test them with data-based experiments and examples. Instead, they can mine the complete set of data for patterns that reveal effects, producing scientific conclusions without further experimentation" (Prensky 2009; see Kitchin 2014, for a critical overview).

9 Jouni Häkli correctly pointed out that subjective judgement plays "upstream" in qualitatively-driven research as well, as it shapes "conceptual, philosophical and ontological starting points" (in his words). I perfectly agree, and this is why I use of the term "mainly" in this sentence. Still, I have two responses: one, that the concepts of positionality and reflexivity have been developed - in qualitatively-oriented research - exactly to acknowledge and embrace the role of one's own judgement (and even prejudice); and, two, that my main point here is emphasizing the generalized lack of such an acknowledgement in quantitative/positivist research.

${ }^{10}$ As Jouni Häkli and Guntram Herb commented, this is a "deliberately mechanistic" (in Häkli's words) and, indeed, reductionist metaphor. Indeed, my goal is not so much using the study of concrete to reflect on social research latu sensu, but rather using it to focus on the differences among methodological and epistemological approaches.

${ }^{11}$ A caveat is necessary from a critical criminological standpoint (e.g. Sutherland \& Cressey 1978; Reiner 2016). One should always remind that crime statistics describe "reported crimes", that is, those crimes that are known to the police and the judiciary, which definitely do not correspond to the totality of crime as a social phenomenon. Reported crime is heavily influenced by the likeliness that a particular crime is reported, by reporting methodologies and by police priorities - certain crimes, for instance drug crimes, are almost never reported and are thus registered only when actively enforced by the police, which may prioritize this or that typology of crime, this or that location for their activity. More than that, crime itself is a socio-political construction, as many activities that cause harm are not legally defined as crimes - think of the fact that "honor killing", that is, killing a wife, is still legal in many countries and was legal in many more just a few decades ago. As such, using crime statistics to conclude that "crime is high in the projects" may be problematic in the first place. Moreover, one could hypothesize that (Ellen and her colleagues (2012) did not consider this possibility), having policing 
been historically particularly aggressive with (poor, mostly Black or Latinx) people living in public housing, the dispersion of those households may be followed by a "dispersion of policing" and, ceteris paribus, contribute to the dispersion of (reported) crime. That said, I will nonetheless consider reported crime as crime - like the article under analysis does - for the sake of the argument and because incorporating those reflections would just add strength to the point I will make about the uncertainty surrounding findings based on crime data.

12 In particular, Ellen and her colleagues (2012) were prompted by the conclusions of a journalistic report on the case of Memphis published on The Atlantic (Rosin 2008).

${ }^{13}$ For a brief presentation of the principle, see note 8 above.

${ }^{14}$ A list of some of the simplifications and problems they point out (Ellen et al. 2012, 557-558 and Appendix 1) follows: crime data are collected at the census tract scale for all cities but one, where they are available at the "neighborhood" level (usually made up of two or three census tracts); voucher data are missing in some cities during some periods of time (in some cities they are not available for the large majority of years in the period of study); anomalies on voucher data are found and attributed to geocoding problems (census track ID is missing, each year, in 8 to $20 \%$ of cases; in about $2 \%$ of tract/ years values deviate sharply from precedent and following years); demographic data are available only for 1990, 2000 and an average for 2005-2009.

${ }^{15}$ The most evident example of this is the simplification and spectacularization of research findings by mass media - epitomized by sentences like "scientists say...", "according to [insert highly-ranked university]..." While researchers cannot automatically be blamed for the simplifications and distortions of science reporting, this trend has fed back into the way quantitative/positivist social research is carried out, as researchers are increasingly pushed to produce novel, confirmatory, "groundbreaking" findings in order to publish in top-ranking journals. One of the effects is the growing concern with "p-hacking", the use of various strategies (from data mining to unduly influencing data collection techniques) to forcefully extract statistically significant findings from vast collections of data - see the overview by Head and colleagues (2015) and the (in)famous case of the retraction of several articles by food behavior scientist Wansink (Resnick \& Belluz 2018).

${ }^{16}$ In his work on austerity politics, Blyth (2013, $32 \mathrm{ff}$.) focuses on the role played by models - based on neoclassical understandings of economics and used in the financial industry to measure the risk of loss from investments - in justifying the decisions that brought to the 2007 financial crash. According to the metrics provided by such technologies, systemic crises of financial markets - those very crises that have recurrently happened during the last century or so - should basically never occur.

${ }_{17}$ Guntram Herb suggested that the metaphor is not fully applicable for two reasons: first, because concrete has no agency or, at the very least, it has much less agency than humans have; and, second, because the testing of a structure is essentially about true or false ("will the concrete hold?"), while social research deals with less clear outcomes. Beyond reiterating that this metaphor is above all useful to focus on differences among paradigms (see note 10), let me add a couple reflections. First, let us not forget that there are both positivist and post-positivist perspectives that would conceptualize agency quite differently. For instance, radical structuralism would suggest that the individual human being under a capitalist system is not really more free to act than an individual grain within a concrete conglomerate; and Actor Network Theory would maybe contest that the point is measuring and comparing the agency of concrete and human beings - and rather advocate considering agency as the network of relationships among them. At any rate, second, it seems to me that applied quantitative/ positivist research prioritizes seeking "solutions" to social problems - that is, it often mimics the true/ false approach of structure testing. Here, I wish to add that the core endeavor of critical social research (see note 5) is precisely that of questioning the definition of social problems as opposed to seeking direct, (allegedly) neutral and technical, solutions to them - see Gusfield's (1989) discussion of the relationship between "political issues" and "social problems", and my transposition of his argument to the field of urban security (Tulumello 2017).

${ }^{18}$ I believe virtually anyone has, at least once in their life, received (and given!) a review that suggested rejection on the basis of comments that basically denied the very epistemological or ontological assumptions of the manuscript under analysis. The common comment on the impossibility to generalize from one case often tells precisely of the incapacity, on the side of the reviewer, to 
conceptualize that valid social research exists that has no interest in producing generalizations in the first place.

${ }_{19}$ One such attempt is the project of the school of transdisciplinarity led by Nicolescu (see Nicolescu 2010, for a summary), which posits that different "levels of reality" exist, and that every discipline is incomplete because it has to remain within one of those levels. This breaks open with classical rational logic and its axioms of identity and non-contradiction (ibid., 29): the idea, at the core for instance of classical physics, that "A is A" and "A cannot be not-A". As quantum mechanics has shown that entities exist that are at the same time A and not-A, the existence of different levels of reality explains how both classical physics and quantum mechanics can be internally correct and rigorous despite the inherent contradictions among their core assumptions and their findings.

20 Spoiler alert: I am referring to Adams' epic sci-fi series The Hitchhiker's Guide to the Galaxy, which revolves around the research of the answer to the "Ultimate Question of Life, the Universe and Everything" - which eventually turns out being... "42".

${ }^{21}$ Another metaphor for scientific knowledge is Spencer's (1863) "sphere" floating in a space of ignorance. As the sphere grows, also the surface of contact with ignorance grows, allowing for both a pessimist and an optimist interpretation: if the amount of knowledge is represented by the radius of the sphere, this grows more slowly than the surface, meaning that the process will produce a relative increase of ignorance; if knowledge is the volume of the sphere, then it grows faster than the surface, and ignorance will relatively decrease in time. While Spencer's sphere is way a more elegant metaphor than my cathedral, it is quite typical of a positivist conception of knowledge as a homogeneous, harmonic totality, which makes scarce space for conflict, debate, contradiction and the messiness of the real world.

\section{References}

Blyth, M. (2013) Austerity: The History of a Dangerous Idea. Oxford University Press, Oxford.

Bryman, A. (1984) The debate about quantitative and qualitative research: a question of method or epistemology? The British Journal of Sociology 35(1) 75-92. http://doi.org/10.2307/590553

Desch, M. C. (2019) How political science became irrelevant. The field turned its back on the Beltway. The Chronicle of Higher Education 27.2.2019. <www.chronicle.com/article/How-Political-ScienceBecame/245777/> 26.4.2019.

Ellen, I. G., Lens, M. C. \& O'Regan, K. (2012) American murder mystery revisited: do housing voucher households cause crime? Housing Policy Debate 22(4) 551-572. https://doi.org/10.1080/10511482. 2012.697913

Flyvbjerg, B. (2001) Social Science Matter: Why Social Inquiry Fails and How it Can Succeed Again. Cambridge University Press, Cambridge. https://doi.org/10.1017/CB09780511810503

Flyvbjerg, B. (2004) Phronetic planning research: theoretical and methodological considerations. Planning Theory and Practice 5(3) 283-306. https://doi.org/10.1080/1464935042000250195

Flyvbjerg, B. (2006) Five misunderstandings about case-study research. Qualitative Inquiry 12(2) 219-245. https://doi.org/10.1177/1077800405284363

Gusfield, J. R. (1989) Constructing the ownership of social problems: fun and profit in the welfare state. Social Problems 36(5) 431-441. https://doi.org/10.2307/3096810

Hanson, B. (2008) Wither qualitative/quantitative?: grounds for methodological convergence. Quality and Quantity 42(1) 97-111. https://doi.org/10.1007/s11135-006-9041-7

Head, M. L., Holman, L., Kahn, A. T. \& Jennions, M. D. (2015) The extent and consequences of p-hacking in science. PLoS Biology 13(3) e1002106. https://doi.org/10.1371/journal.pbio.1002106

Kitchin, R. (2014) Big data, new epistemologies and paradigm shifts. Big Data and Society 1(1). https:// doi.org/10.1177/2053951714528481

Marcuse, P. (2010) In defense of theory in practice. City: Analysis of Urban Trends, Culture, Theory, Policy, Action 14(1-2) 4-12. https://doi.org/10.1080/13604810903529126

Marx, K. (1978 [1844]) For a ruthless criticism of everything existing. In Tucker, R. C. (ed.) The MarxEngels Reader, 12-15. $2^{\text {nd }}$ ed. W.W. Norton \& Company, New York.

Nicolescu, B. (2010) Methodology of transdisciplinarity - Levels of reality, logic of the included middle and complexity. Transdisciplinary Journal of Engineering and Science 1(1) 19-38.

Pepinsky, T. (2016) Methods debates for humanists. Tom Pepinsky 17.06.2016. <https://tompepinsky. com/2016/06/17/methods-debates-for-humanists/> 26.4.2019. 
Prensky, M. (2009) H. sapiens digital: from digital immigrants and digital natives to digital wisdom. Innovate. Journal of Online Education 5(3) article 1.

Reiner, R. (2016) Crime. The Mystery of the Common-sense Concept. Polity, Cambridge.

Resnick, B. \& Belluz, J. (2018) A top Cornell food researcher has had 15 studies retracted. That's a lot. Vox 24.10.2018. <wWW.vox.com/science-and-health/2018/9/19/17879102/brian-wansink-cornellfood-brand-lab-retractions-jama> 26.4.2019.

Rosin, H. (2008) American murder mystery. The Atlantic July/August 2018. <www.theatlantic.com/ magazine/archive/2008/07/americanmurdermystery/306872/> 26.4.2019.

Spencer, H. (1863) First Principles. Williams and Norgate, London.

Suggelkow, N. (2007) Persuasion with case studies. Academy of Management Journal 50(1) 20-24. https://doi.org/10.5465/amj.2007.24160882

Sutherland, E. \& Cressey, D. R. (1978) Criminology. Lippincott, Philadelphia.

Tulumello, S. (2017) Toward a critical understanding of urban security within the institutional practice of urban planning: the case of the Lisbon Metropolitan Area. Journal of Planning Education and Research 37(4) 397-410. https://doi.org/10.1177/0739456X16664786

Venturini, T., Jacomy, M., Meunier, A. \& Latour, B. (2017) An unexpected journey: a few lessons from sciences po médialab's experience. Big Data and Society 4(2) 205395171772094. https://doi. org/10.1177/2053951717720949

Yin, R. (1994) Case Study Research. Design and Methods. Sage, Thousand Oaks. 